\title{
Research on Personalized E-Learning System Using Fuzzy Set Based Clustering Algorithm
}

\author{
Feng $\mathrm{Lu}^{1,2}, \mathrm{Xin} \mathrm{Li}^{1,2}$, Qingtang Liu ${ }^{1}$, Zongkai Yang ${ }^{1}$, Guoxin Tan ${ }^{1}$, and Tingting $\mathrm{He}^{1}$ \\ ${ }^{1}$ Engineering \& Research Center for Information Technology on Education, Huazhong \\ Normal University Wuhan 430079, China \\ ${ }^{2}$ Science and Technology of Education Department, Hunan University Of Science and \\ Engineering Yongzhou 425100, China \\ lufengmaster@126.com
}

\begin{abstract}
Personalized service is becoming increasingly important, especially in E-learning field. Most personalized E-learning systems only take learners preferences, interests and browsing behaviors into consideration. These systems usually neglect considering whether the learners ability and the difficulty level of recommended learning materials are matched to each other or not. This paper proposes a personalized E-learning system using fuzzy set based clustering algorithm which considers both course materials' difficulty and learners' ability to provide appropriate learning stuffs for learners individually, to help learners learn more efficiently and effectively.
\end{abstract}

Keywords: Difficulty level; Learner ability; Fuzzy clustering algorithm.

\section{Introduction}

As the Internet gains wide popularity around the world, high diversity of the learners on the Internet brings new challenges to the traditional "one-size-fit-all" learning model [1]. So it's of great importance to provide a personalized system which can automatically adapt to the interests and levels of learners' ability.

Cluster analysis is a technique to divide the data set in such a way that cases assigned to the same cluster should be as similar as possible whereas two objects from different clusters should be as dissimilar as possible[2]. In the proposed system, we strive to model learners' ability to group similar learners into homogeneous classes, and the fuzzy clustering algorithm is a good choice which we adopt.

\section{Personalized E-Learning System}

\subsection{System Architecture}

In the proposed personalized E-learning system, there are five layers. Database layer consists of user account, course and user profile databases. The user account database records the basic information. The user profile database contains learners' trajectory. The course database contains the course materials and their corresponding difficulty 
levels. Users' feedback acquisition layer consists of questionnaire, quiz and behavior record. Through the questionnaire and quiz after each material, system can collect the main information of the learners' ability and the materials' difficulty level. Through the record of the learners' behavior, it can provide the system with the proof of the feedback and the information of the learners' ability and preferences. Data mining and inference layer is to extract and infer the materials' difficulty level and the learners' ability from the data of database layer. Recommend and push layer uses the learners' new abilities to select appropriate course materials for learners individually. Presentation layer provides a register, login, searching and browsing interface to let the users become registered ones, help learners retrieve specified course materials.

\subsection{The Key Techniques and Algorithms}

\subsubsection{Calculate Difficulty Parameters of Course Materials Dynamically}

The course materials' difficulty level is classified into five points: \{very hard, hard, moderate, easy, and very easy\}, depicted as $\operatorname{Dif}_{1}, \mathrm{Dif}_{2}, \mathrm{Dif}_{3}, \mathrm{Dif}_{4}, \mathrm{Dif}_{5}$ [3]. Dexp denotes the experts' decision of material difficulty level, which can be calculated in formula (1).

$$
\mathrm{D}_{\exp }=\sum_{n=1}^{5} \frac{C_{n}}{C_{\exp \text { erts }}} D \text { if }
$$

Where $C_{n}$ denotes the number of experts that select the difficulty level of $\mathrm{Dif}_{n}, \mathrm{C}_{\text {experts }}$ denotes the fixed number of experts, as a constant here.

The materials difficulty parameters assessed by the learners and teachers can be calculated by formula (2), marked as $\mathrm{D}_{\text {stu }}$ and $\mathrm{D}_{\text {tea }}$ respectively.

$$
D_{\text {stu }}=\sum_{m=1}^{5} \frac{C_{m}}{C_{\text {learners }}} \text { Dif }, D_{\text {tea }}=\sum_{j=1}^{5} \frac{C_{j}}{C_{\text {teachers }}} \text { Dif } \text { if }_{j} .
$$

Where $\mathrm{C}_{\mathrm{m}} / \mathrm{C}_{\mathrm{j}}$ denotes the number of learners/teachers that select the difficulty level of $\mathrm{Dif}_{\mathrm{m}} / \mathrm{Dif}_{\mathrm{j}}, \mathrm{C}_{\text {learners }} / \mathrm{C}_{\text {teachers }}$ denotes the number of learners/teachers who have already studied/used the course material.

The adjusted difficulty parameter of a certain material is calculated by formula (3):

$$
D=w_{1} \times D_{\text {exp }}+w_{2} \times D_{\text {tea }}+\left(1-w_{1}-w_{2}\right) \times D_{\text {stu }} .
$$

Where $\mathrm{w}_{1}$ and $\mathrm{w}_{2}\left(0<1-\mathrm{w}_{1}-\mathrm{w}_{2}<\mathrm{w}_{2}<\mathrm{w}_{1}<1\right)$ denote the weight of the course difficulty parameters the experts recommend and the teacher users decide respectively.

\subsubsection{Estimate the Level of Learner Abilities}

In E-learning systems, there are many variables that determine the learners' ability. Herein, we just consider the most important ones. We form a factor set for the system, which is depicted as: $\mathrm{U}=\left\{\mathrm{u}_{1}, \mathrm{u}_{2}, \mathrm{u}_{3}, \mathrm{u}_{4}, \mathrm{u}_{5}\right\}$, in which $\mathrm{u}_{1}$ denotes the time spent on each material, $\mathrm{u}_{2}$ denotes questionnaire feedback after each material, $\mathrm{u}_{3}$ denotes quiz feedback after each material, $\mathrm{u}_{4}$ denotes times clicking on antecedent material links, $\mathrm{u}_{5}$ denotes random mouse move and click. The weight set can be depicted as: $\mathrm{W}=\left\{\mathrm{w}_{1}, \mathrm{w}_{2}, \mathrm{w}_{3}, \mathrm{w}_{4}, \mathrm{w}_{5}\right\}$, which we adopts the value as $\mathrm{W}=\{0.2,0.35,0.3,0.1,0.05\}$. 
(1) $\mathrm{u}_{1}$ : the time spent on each material, with the weight $\mathrm{w}_{1}$.

The assessment set of $\mathrm{u}_{1}$ is depicted as $\mathrm{V}_{1}=$ \{very long, long, moderate, short, very short $\}$, the corresponding weight set is depicted as $A=\left\{a_{1}, a_{2}, a_{3}, a_{4}, a_{5}\right\} . T_{i}$ represents a learner's browsing time on a certain material. We compute the learners' average browsing time on a certain material [4], depicted as formula (4).

$$
\bar{T}=\frac{T_{1}+T_{2}+\cdots+T_{n}}{n}=\frac{\sum_{i=1}^{n} T_{i}}{n} .
$$

Where $\mathrm{n}$ represents the total number of learners that has browsed the certain material. Notably, the $\mathrm{T}_{\mathrm{i}} \mathrm{s}$ which are too big and too small are excluded.

Then we can use statistic method to calculate the ratio of each assessment element in assessment set $\mathrm{V}_{1}$ for a certain material. We defined the time range as formula (5):

$$
T_{\text {range }}=(1+b) \times \bar{T},\left(b=\frac{T-\bar{T}}{\bar{T}}\right)
$$

The variable $b$ denotes the bias of the time period. The membership degree of different time range corresponding to $\mathrm{V}_{1}$ is defined as formula (6):

$$
a_{1}=\frac{1_{T_{1}}+1_{T_{2}}+\cdots+1_{T_{i}}}{n},\left(c_{1} \leq b \leq c_{2},\left(T_{\text {range }} \mid b=c_{1}\right) \leq T_{i} \leq\left(T_{\text {range }} \mid b=c_{2}\right)\right) .
$$

Where $\mathrm{a}_{1}$ denotes one of the assessment set element $\{$ very long $\}, \mathrm{T}_{1}, \mathrm{~T}_{2}, \ldots, \mathrm{T}_{\mathrm{i}}$ denote the learners that consume the time between $\mathrm{T}_{\text {range }} \mathrm{b}=\mathrm{c}_{1}$ (computing $\mathrm{T}_{\text {range }}$ when $\mathrm{b}=\mathrm{c}_{1}$ ) and $\mathrm{T}_{\text {range }} \mathrm{l} \mathrm{b}=\mathrm{c}_{2}$, the numerator $1_{T_{1}}+1_{T_{2}}+\cdots+1_{T_{i}}$ denotes the number of a group of learners of fore mentioned kind, $\mathrm{n}$ denotes the total learners that has browsed the material. Notably, the constant $c_{1}$ and $c_{2}$ in formula (6) are as cutoff point; their values are acquired through experiment. The other weight calculation method resembles $\mathrm{a}_{1}$ 's, where the value $b$ is differentiated every time.

(2) $\mathrm{u}_{2}$ : questionnaire feedback after each material, with the weight $\mathrm{w}_{2}$.

The assessment set of $\mathrm{u}_{2}$ is depicted as $\mathrm{V}_{2}=$ \{completely understand, understand, moderate, little of understanding, completely not understand $\}$, and its corresponding weight set is depicted as $B=\left\{b_{1}, b_{2}, b_{3}, b_{4}, b_{5}\right\}$. We use the statistic method to calculate the ratio of each assessment element in assessment set $\mathrm{V}_{2}$ for a certain material.

(3) $\mathrm{u}_{3}$ : quiz feedback after each material, with the weight $\mathrm{w}_{3}$.

The assessment set of $\mathrm{u}_{3}$ is described as $\mathrm{V}_{3}=\{$ very good, good, moderate, bad, very bad $\}$, and its corresponding weight set is depicted as $C=\left\{\mathrm{c}_{1}, \mathrm{c}_{2}, \mathrm{c}_{3}, \mathrm{c}_{4}, \mathrm{c}_{5}\right\}$. The calculation method of the weight set of $\mathrm{C}$ resembles the B's fore mentioned.

(4) $\mathrm{u}_{4}$ : times clicking on antecedent material links, with the weight $\mathrm{w}_{4}$.

The assessment set of $\mathrm{u}_{3}$ is described as $\mathrm{V}_{4}=$ \{very many, many, moderate, few, very few $\}$, and its corresponding weight set is depicted as $D=\left\{\mathrm{d}_{1}, \mathrm{~d}_{2}, \mathrm{~d}_{3}, \mathrm{~d}_{4}, \mathrm{~d}_{5}\right\}$. The calculation method of the weight set of $\mathrm{D}$ resembles the one of $\mathrm{B}$ fore mentioned. 
(5) $\mathrm{u}_{5}$ : random mouse move and click, with the weight $\mathrm{w}_{5}$.

The assessment set of $\mathrm{u}_{3}$ is described as $\mathrm{V}_{5}=$ \{very many, many, moderate, few, very few $\}$, with its weight set $E=\left\{e_{1}, e_{2}, e_{3}, e_{4}, e_{5}\right\}$. The calculation method of $E$ resembles the ones of $\mathrm{u}_{1}$ and $\mathrm{u}_{4}$. Herein, we don't mention any more about the algorithm.

Now, we can calculate the learners' abilities. Just take one group of data for example. The factor weight set $\mathrm{W}=\{0.2,0.35,0.3,0.1,0.05\}$, assume that we have the result data of a learner $X$, whose vector set is calculated already, his/her vector set result is $\mathrm{v}_{\mathrm{X}}=(0.9,0.5,0.8,0.8,0.8)$. The learner $\mathrm{X}$ 's ability is calculated as formula (7):

$$
\mathrm{X}_{\mathrm{ability}}=\mathrm{W} \times v_{x}=0.715 \text {. }
$$

Before we rank the learner X's ability level, we have to classify the number $0 \sim 1$ into five points: \{Very high ability, high ability, moderate ability, low ability, very low ability . Herein, X's ability result is 0.715 , is between the $\{$ high ability $\}$ thresholds from the system inference.

After reevaluates learners' abilities and recalculates the course materials difficulty levels, the system can recommend materials to learners based on learners' ability.

\section{Conclusion}

The system provides personalized learning according to course materials visited by learners and their responses, the experiment results show that the proposed system precisely provides personalized course material recommendations based on learners ability, and moreover accelerate learners' learning efficiency and effectiveness.

\section{Acknowledgement}

This Research is supported by the Cultivation Fund of the Key Scientific and Technical Innovation Project, Ministry of Education of China (NO705038). It's also partly supported by the Special Scientific Research Fund for Doctor Subjects of Universities (NO20050511002) and Hubei Nature Science Fund (NO2006ABC011).

\section{References}

1. Li X, et al.:A Personalized E-learning System Based on User Profile Constructed Using Information Fusion. DMS'2005

2. Döing C, Lesot M.J, Kruse R. :Data analysis with fuzzy clustering methods. Computational Statistics \& Data Analysis 51(2006)192 - 214

3. Chen C.M., et al.: Personalized E-learning system using Item Response Theory. Computers \& Education 44 (2005) 237-255

4. Huang C.J., et al. :Implementation and performance evaluation of parameter improvement mechanisms for intelligent E-learning systems. Computers \& Education (2005) 